\title{
The health status of African-American men: improving our understanding of men's health challenges
}

\author{
Jean J.E. Bonhomme
}

\section{Introduction}

The awakening to the existence of health disparities has spurred concern about men's health issues. Questions have arisen as to why racial and ethnic minorities have a lower average life expectancy, greater incidence or prevalence of life-limiting diseases, and a less favorable prognosis, even when diagnosed with the same diseases. 'Gender and health' parallels 'race and health' because any intellectually honest discussion about health disparities between diverse demographic groups must take account of the striking variations in longevity and health outcomes associated with gender. The health status of minority men can potentially serve to guide our thinking about men's health challenges in various areas.

Jean J.E. Bonhomme, MD Founder of the National Black Men's Health Network, Emory University, Rollins School of Public Health, Atlanta, GA, USA

E-mail:

jbonhom@sph.emory.edu

Online 23 September 2004

\section{The health status of African- American men serves as a compelling example of health disparity associated with gender}

The concern that led me to become involved with men's health was the statistic that in the 1980s the average life expectancy for African-American men in the United States was below retirement age. Men become eligi- ble for Medicare and Social Security benefit at the age of 65 years in the US, but AfricanAmerican men were only living until their early sixties. Minority men's health challenges exemplify gender-related health disparities which are so overwhelming in magnitude that they cannot be ignored, dismissed or denied.

In the United States, African-American men have the highest death rates per 100,000 population due to heart diseases, cancer, AIDS, homicide, kidney disease, chronic liver disease/cirrhosis and many other leading causes of death. In 1995, the heart disease death rate among African-American men was $29 \%$ higher than the rate for American white men [1]. In addition to the highest overall death rate, African-American men died earlier. Among African-American men $40 \%$ of those who died from cardiac deaths were younger than 65 years (defined as premature death) compared with $21 \%$ for white men. In 1990 , the leading cause of death for all races was heart disease, with an age-adjusted death rate per 100,000 population of 275.9 for African-American men compared with 202.0 for white men, 168.1 for African-American women, and 103.1 for white women. After a mean follow-up of 16 years, age-adjusted end-stage renal disease (ESRD) incidence was 13.90 per 100,000 person-years in white men and 44.22 per 100,000 personyears in African-American men. Higher blood 
pressure and lower socioeconomic status was associated with higher incidence of ESRD in both groups [2].

Homicide ranks thirteenth in the US among the leading causes of death. Among AfricanAmerican men of all ages, homicide ranks fifth but is the second leading cause of death for the age group 15-24 years. Over the course of a lifetime, an African-American man in the US has a 1 in 30 chance of being murdered, as opposed to a 1 in 132 for African-American women, a 1 in 179 for white men and a 1 in 495 for white women [3].

The National Cancer Institute's Surveillance, Epidemiology and End Results Program (SEER) found that for men of all races, the prostate gland was the leading site for incident cancer [4]. The African-American men's rate per 100,000 population was 163.6 as opposed to 128.5 for white men. From 1983 to 1989 the 5 -year survival rate for African-American men with prostate cancer was $64.4 \%$, compared with a survival rate of $79.4 \%$ for white men in the SEER program.

The key factor that shows these gender-associated health disparities is that the greatest difference in longevity is typically between men of minority groups and white women. In the US there is at present about 12 to 13 years difference in life expectancy between African-American men and white women. It is difficult to conceptualize so striking a difference as natural, acceptable or inevitable. Markedly diminished life expectancies are also characteristic of racial minority populations in other parts of the world, e.g. the indigenous population of Australia.

\section{The health status of African- American men indicates that disparities in longevity and health outcomes similar in magnitude to the difference between the genders can exist in the absence of biologically based gender differences}

For decades the longevity gap between the sexes was presumed to be inherent and biologically determined. To assert that the longevity difference between the races could be similarly of biological origin was however far less poli- tically acceptable. There is no sex chromosome difference and not a great deal of demonstrable hormonal difference between people of the same sex but different races. However, the differences in health and longevity are often just as large as those between the sexes. The existence of disparities in longevity between races does not disprove the existence of biologically based differences between the sexes. These racial disparities do however show that factors that are almost certainly environmental in origin can cause substantial differences in longevity and health outcomes. This raises the question of the extent to which the gender longevity gap is also environmentally mediated.

\section{African-American male health challenges are not based solely upon racial issues, but are based in large part upon factors that are inseparable from the issues facing males as a gender}

In the US over 95\% of workers in the ten most hazardous jobs are men, and over $90 \%$ of occupational deaths occur among men. Injuries of many types, including motor vehicle accidents, chemical exposures, suicide and homicide, as well as lack of participation in the health care system all figure prominently in the higher death rates among men and boys. To explain what limits the lives of AfricanAmerican men, it is vitally important to consider not just the racial factors but also the cultural and environmental factors to which men as a gender are subjected.

Frequently, men are socialized as part of their gender role training to have stoic attitudes towards pain and fear. Stoic attitudes are often culturally prized among men. To train himself for physical labor jobs, the worker may need to develop a high tolerance for discomfort. Often, men are brought up to regard "giving in" to pain as weakness, resting from fatigue as laziness, and feeling fear or running from danger as cowardly.

During childhood and adolescence boys are told "brave boys don't cry" or for sports injury "take it for the team." Consequently at 50 years of age men may dismiss chest pain as "only indigestion." Men are often taught from 
childhood that if you ignore something painful, it will go away with time. This is usually true for minor ailments and injuries during childhood. In middle age however mild symptoms can indicate early progressive disease states that may go from manageable to incurable if not addressed promptly. Studies have shown a number of characteristics inherent in traditional male gender role socialization are responsible for men's less frequent use of therapeutic services [5]. Such characteristics are believed to include achievement orientation, restricted emotional expression, instrumental nature, self-reliance, and restricted expression of same-sex affection.

The demands of the work role may reinforce the cultural expectations placed upon men. Men are disproportionately represented in physically hazardous work, such as military and manual labor jobs. Heavy labor jobs may create a need to disconnect from feelings and emotions just to get through the job. Painful and hazardous work may lead directly to serious injury and even loss of life as a result of onthe-job conditions. When a person learns to ignore bodily discomfort during the workweek, he will not start feeling again after leaving work. Being habituated to ignore uncomfortable conditions such as extreme weather or an aching back at work increases the chances that other, more serious discomfort (such as chest pain) is also ignored.

Cultural indifference to pain and fear is believed by some researchers to be especially pronounced among African-American men [6]. Many of the factors that limit the health and lives of men may affect African-American men disproportionately to other men. AfricanAmerican men are overrepresented in manual labor jobs that are physically painful and hazardous. In the past, some dirty and dangerous jobs were referred to as "Negro work."

\section{The health status of African- American men illustrates the devastating consequences of delay in seeking health care and points out contributing causes of such delay}

It is well known that African-American men in the US are more likely to be diagnosed with prostate cancer than white men and have less favorable prognoses after diagnosis. African-American men do however have health outcomes comparable to white men if diagnosed at the same stages of prostate cancer and afforded similar treatment [7]. Minority men in the age group 18-64 years (black and Hispanic) in all income brackets from poor to high-income are twice as likely to have had no physician contact in the past year as minority women and less likely to carry health insurance than their female counterparts. Lack of participation in health care among minority men is not entirely attributable to lack of financial resources or health insurance. African-American and Hispanic men in middle and high-income groups have been shown to be less likely to have seen a physician in the previous year than the poorest cohort of their female counterparts [8].

The predicament of African-American women is similar. Breast cancer in AfricanAmerican women likewise carries a worse prognosis than for white American women, but this is also largely attributable to later presentation for medical care. Much of the disparity in health outcomes between races may be attributed to later medical intervention in the course of disease. In addition, delays in seeking health care may contribute to disparities between the sexes. American men were found to be less likely to have seen a physician in the previous year and less likely to have a regular doctor than women, and frequently resist seeking medical care even when ill or in pain [9].

Attitudinal reasons for health care avoidance are also evident. African-Americans distrust the health care system, especially African-American men. Such misguided medical experiments as the Tuskegee syphilis trials (1932-1972) contributed to this distrust. In the Tuskegee experiment, African-American men were told that they were being treated for syphilis when they were only being observed to document the natural history of the disease [10]. Experimentation on men has also taken place in the military. Fear of being used as guinea pigs may be a barrier to participation in health care among veterans and other groups as well. 
The health status of AfricanAmerican men shows that poor health among men negatively affects the health of women and children, pointing to men's health as an essential but frequently overlooked component of community health

The Centers for Disease Control and Prevention (CDC) estimates that 1 out of every 50 AfricanAmerican men living in the US is HIV infected. However, HIV infects 1 out of 160 African-American women as well. It is doubtful that HIV could have attained such alarming prevalence among African-American women had it not first become widespread among African-American men. When health problems among men are allowed to proliferate unchallenged, problems for women's health soon follow.

The economics of the family are adversely affected by male health problems. Illness among men often diminishes work productivity. When men become disabled or die, family income is usually reduced, often in the face of additional health care expenses. Cross-sectional and longitudinal data suggest that the end of marriage correlates with higher poverty rates among women [11]. Over $25 \%$ of divorced women fall into poverty for at least some time during the first 5 years after separation following marriage breakdown, but $40 \%$ of widows do so as well. Furthermore, increases in death rates have been observed after widowhood, with all-causes mortality doubling in the first month after spousal loss [12].

In addition, birth defects have been associated with advanced paternal age, military service, chemical, drugs, alcohol, and tobacco exposure among fathers. Among offspring, advanced paternal age has been associated with increased risk of preauricular cyst, nasal aplasia, cleft palate, hydrocephalus, pulmonic stenosis, urethral stenosis, and hemangioma [13]. Fathers' cigarette smoking has been associated with cleft lip (with or without cleft palate), hydrocephalus, ventricular septal defect, and urethral stenosis among children [13]. Fathers' alcohol use has been shown to be related to the offspring's risk of ventricular septal defect [13]. Increased rates of acute myelogenous leukemia among the children of fathers who served in the military in Vietnam and Cambodia have been observed through analysis of data from three case-control studies from the Children's Cancer Group [14]. Advanced paternal age at the time of birth of the children is associated with increased risk for adult schizophrenia and schizophrenia spectrum disorders among offspring [15].

No society can expect to attain its full health potential when the health of a major section of its citizens is ignored. Neither men nor women can attain their full potential for health and longevity until the health problems facing both sexes are thoroughly addressed. Increased attention to the health concerns of men should not be seen as antagonistic to meeting the health needs of women and children. Instead, men's health should be welcomed as a logical complement to women's and children's health. Men's health needs to be recognized as an essential component of building a complete and inclusive health care system and achieving optimal community health, both within nations and internationally.
References

[1] Centers for Disease Control and Prevention. Men and heart disease: an Atlas of racial and ethnic disparities in mortality. 2001 (online reference) http://www.cdc.gov/nccdphp/ $\mathrm{cvd} /$ mensatlas/index.html.

[2] Klag MJ, Whelton PK, Randall BL, Neaton JD, Brancati FL, Stamler J. End-stage renal disease in African-American and white men: 16-year MRFIT findings. J Am Med Assoc 1997:277(16):1293-8.

[3] US Bureau of Justice, BJS Data Report USA. Homicide victimization rates by gender, race. 1989. p. 20.
[4] Flack JM, Amaro $H$, Jenkins W, Kunitz S, Levy J, Mixon M, et al. Panel I: epidemiology of minority health. Health Psychol 1995; 14(7): 592-600

[5] Campbell JL. Traditional men in therapy: obstacles and recommendations. J Psychol Pract 1996;2(3):40-5 [summary].

[6] Ronald LB, Sandra ET, editors. Health issues in the black community, 2nd ed. San Francisco, USA: Jossey-Bass Publishers; 2001.

[7] Optenberg SA, Thompson IM, Friedrichs $P$, Barbara W, Stein CR, Kramer B. Race, treatment, and long-term survival from prostate cancer in an equal-access medical care delivery system. J Am Med Assoc 1995;274(20): 1599-605.

[8] Department of Health and Human Services. Health United States. 1998 [Fig. 43].

[9] Sandman D, et al. Out of touch: American men and the healthcare system. Commonwealth Fund men's and women's health survey findings. 2000. http://www.cmwf.org/ programs/women/sandman_outoftouch_ 374.pdf

[10] White RM. The Tuskegee syphilis study. Hastings Center Rep 2002;32(6):4-5. 
[11] Morgan LA. Economic well-being following marital termination: a comparison of widowed and divorced women. J Fam Issues 1989;10(1):86-101.

[12] Jones DR. Office of population censuses and surveys. Heart disease mortality following widowhood: some results from the OPCS longitudinal study. J Psychosom Res 1987; 31(3):325-33.

[13] Savitz DA, Schwingl PJ, Keels MA. Influence of paternal age, smoking, and alcohol consumption on congenital anomalies. Teratology 1991;44(4):429-40.

[14] Wen W-Q, Shu X-O, et al. Paternal military service and risk for childhood leukemia in offspring. Am J Epidemiol 2000;151(3): 231-40.

[15] Brown AS, Schaefer CA, Wyatt RJ, et al. Paternal age and risk of schizophrenia in adult offspring. Am J Psychiatry 2002; 159(9):1528-33. 